DOI 10.37882/2223-2974.2020.09.01

\title{
ТРАНСФОРМАЦИЯ ТЕХНОЛОГИЧЕСКОГО УКЛАДА ПРОМЫШЛЕННОГО ПРЕДПРИЯТИЯ В СОВРЕМЕННЫХ ЭКОНОМИЧЕСКИХ УСЛОВИЯХ
}

\section{TRANSFORMATION OF THE TECHNO- LOGICAL STRUCTURE OF AN INDUSTRIAL ENTERPRISE IN MODERN ECONOMIC CONDITIONS}

\author{
I. Androsova \\ Yu. Polozhentseva \\ O. Kalimov \\ A. Shevtsov
}

Summary: Currently, industrial enterprises continue to feel the effects of the economic crisis caused by the coronavirus pandemic. The current conditions force industrial enterprises to change their approach to development by transforming the technological structure. The purpose of the article is to develop recommendations for the transformation of the technological structure of an industrial enterprise in modern economic conditions. The article is written on the example of a typical chemical industry enterprise. When writing the article, the main problems that hinder the more effective development of the enterprise are identified. To solve these problems, the authors proposed recommendations for mitigating the crisis consequences and entering the path of sustainable growth. At the same time, the authors note that the proposed recommendations and measures are universal and can be applied to other industrial enterprises.

Keywords: industrial enterprises; technological structure; transformation; pandemic; growth opportunities.
Андросова Ирина Владимировна

К.э.н., дочент, ФГБОУ ВО «Юго-Западный государственный университет», г. Курск irinka-rusik@mail.ru

Положенцева Юлия Сергеевна К.э.н., доцент, ФГБОУ ВО «Юго-Западный государственный университет», г. Курск polojenceva84@mail.ru

Калимов Олег Владимирович

К.э.н., дочент, ФГБОУ ВО «Юго-Западный государственный университет», г. Курск

o_kalimov@mail.ru

Шевцов Алексей Николаевич

Аспирант, ФГБОУ ВО «Юго-Западный государственный университет», г. Курск aleksey_shevtsov95@mail.ru

Аннотация: В настоящее время промышленные предприятия продолжают ощущать последствия экономического кризиса, вызванного пандемией коронавируса. Сложившиеся условия заставляют промышленные предприятия менять подход к развитию путем трансформации технологического уклада. Цель статьи заключается в разработке рекомендаций по трансформации технологического уклада промышленного предприятия в современных экономических условиях. Статья написана на примере типичного предприятия химической промышленности. При написании статьи выявлены основные проблемы, препятствующие более эффективному развитию предприятия. Для решения данных проблем авторами предложены рекомендации по смягчению кризисных последствий и выходу на траекторию устойчивого роста. При этом авторами отмечается, что предложенные рекомендации и мероприятия носят универсальный характер и могут быть применимы для других промышленных предприятий.

Ключевые слова: промышленные предприятия; технологический уклад; трансформация; пандемия; возможности роста.

действованного непосредственно в производственном процессе. Проблемы, связанные с доступностью сырья и комплектующих, в полной мере отразились на предприятиях автомобильной, авиационной, энергетической, химической отраслях [2]. Таким образом, сложившиеся условия хозяйствования ориентируют промышленные предприятия на трансформацию существующего технологического уклада для выхода на устойчивую траекторию экономического роста.

Различные решения по поиску новых возможностей роста рассмотрены на примере традиционного пред- 


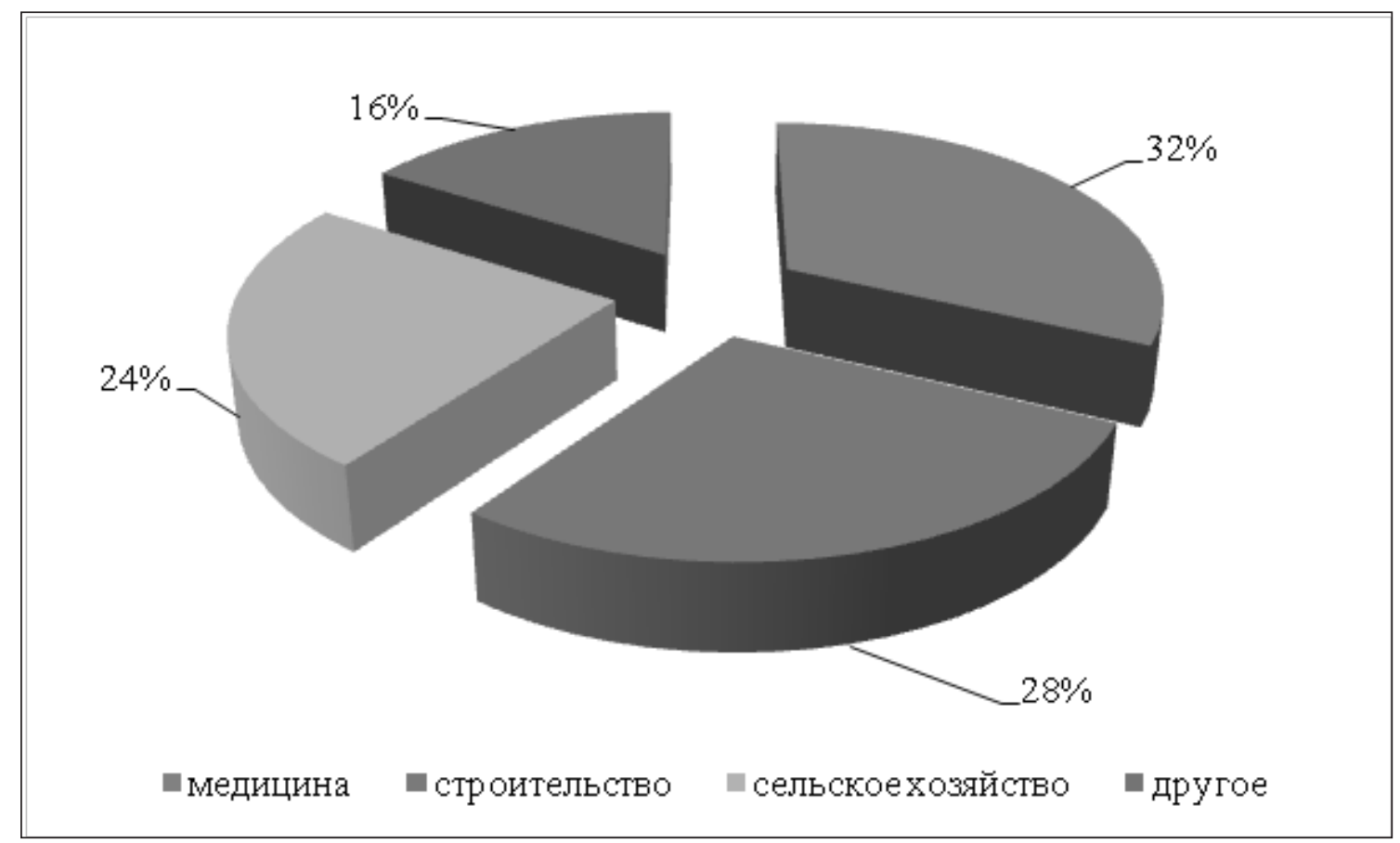

Рис. 1. Отраслевая структура потребления спанбонда [7]

приятия химической промышленности, которое в условиях экономической турбулентности, вызванной пандемией, вынуждено менять формат ведения бизнеса[1, с.144]. Одним из типичных представителей отрасли химической промышленности является предприятие ООО «Курскхимволокно», специализирующееся на производстве полиамидных нитей и волокон. Особенностями любого химического промышленного предприятия являются высокая ресурсоемкость с длительным сроком окупаемости затрат, низкая стратегическая гибкость, сложные межорганизационные отношения в силу ограниченного числа партнеров [5, с.7]. С начала пандемии на предприятии выявлено падение покупательского спроса ввиду сокращения клиентов - заказчиков. Связи с этим, установлены основные проблемы, препятствующие эффективному развитию деятельности промышленного предприятия:

- недостаток собственных возможностей предприятия по поиску партнеров-заказчиков;

- недостаточный учет рыночных возможностей и потенциального спроса на рынке однородных товаров.

Первая проблема заключается в том, что к одной из слабых сторон деятельности предприятия относится отставание в маркетинговых технологиях и отсутствии службы маркетинга. ООО «Курскхимволокно» является крупным промышленным предприятием, использующим в качестве маркетинговых инструментов продвижения продукции: участие в государственных заказах; участие в промышленных выставках; долгосрочные связи.
Вторая выявленная проблема заключается в недостаточном учете рыночных возможностей и потенциального спроса на рынке однородных товаров. Комплексные исследования рыночных потенциальных возможностей [7] выявили существенный спрос производимой продукции на рынке потенциальных клиентов и позволили дать оценку маркетинговым возможностям предприятия, а также позволили систематизировать практические направления оценки открывающихся рыночных перспектив. Современные экономические условия, сложившиеся в условиях пандемии, требуют взвешенного подхода к изучению объема динамики продукции, пользующейся повышенным спросом, к которой в настоящее время относятся средства индивидуальной защиты, маски, используемые в медицине. Основным материалом, который используется при производстве масок и СИЗ, является нетканый материал - спанбонд (рис. 1).

В настоящее время в России функционируют 22 завода по производству спанбонда. Половина заводов сосредоточена в Центральном Федеральном округе, пять заводов находится в Приволжском Федеральном округе; четыре - в Южном Федеральном округе; два в Уральском Федеральном округе, один в Кавказском федеральном округе. Отметим, что Курский регион не входит число тех регионов, на территории которых функционируют заводы по производству спанбонда. Преимущественно заводы сосредоточены в Москве и Московской области.

Выявленные проблемы промышленного предприятия позволили сформулировать ряд рекомендаций, на- 


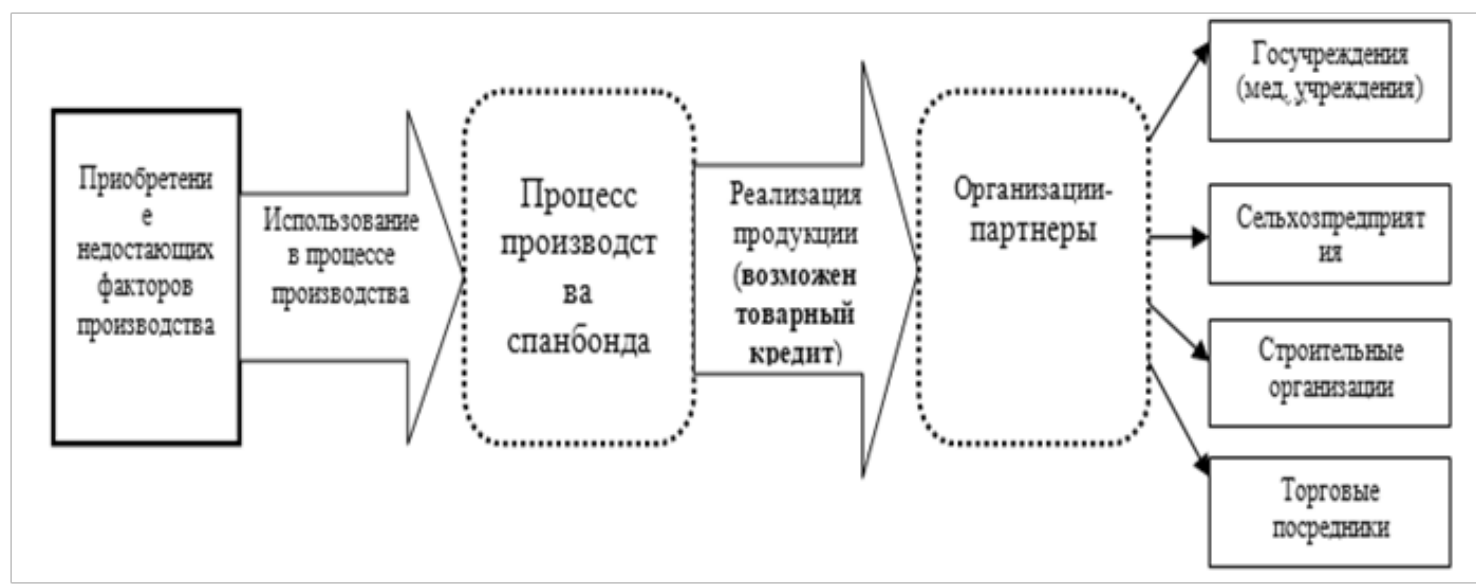

Рис. 2. Локальный пример партнерства при реализации бизнес-идеи по производству спанбонда

правленных на минимизацию их последствий [6, с.300].

Для устранения недостатка собственных возможностей предприятия по поиску партнеров-заказчиков предлагается использовать различные промышленные торговые электронные площадки и порталы, участие в которых обеспечит владение информацией о возможных заказах и потенциальных партнеров. Среди промышленных торговых площадок и порталов выделяются такие как: Метапром, PromPortal.su, EquipNet.ru, Пульс цен и другие. Важным источником поиска партнеров может стать биржа субконтрактов, функционирующая на базе Курского регионального центра производственной кооперации и субконтрактации. Биржа субконтрактов представляет собой площадку, с помощью которой организуются прямые переговоры между заказчиками и их потенциальными поставщиками. При этом биржа субконтрактов содержит постоянно обновляемые базы данных поставщиков, заказов, и заказчиков, что позволяет ускорить процесс поиска партнеров.

Для решения проблемы сокращения разрыва между потенциальным и реальным спросом предлагается реализовать на базе промышленного предприятия инвестиционный проект по запуску производственной линии для производства спанбонда - нетканого материала, используемого при пошиве медицинских масок, средств индивидуальной защиты, укрывного материала и прочих товаров.

Для успешной реализации проекта предлагается разработать механизм бизнес-партнерства. В целях сбыта произведенного спанбонда необходимо найти клиентов, к которым относятся швейные предприятия, специализирующиеся на выпуске медицинских масок и костюмов, которые в настоящее время пользуются повышенным спросом. На рисунке 2 представлен локальный пример партнерства при реализации бизнес-идеи по производству спанбонда на базе промышленного предприятия.
Для поиска партнера можно воспользоваться рассмотренными ранее торговыми площадками, в том числе и биржой субконтрактов. Привлечь потенциальных клиентов возможно предоставлением товарного кредита на начальном этапе взаимодействия. Подобная кооперация позволяет объединить усилия отдельных производственных предприятий для реализации крупномасштабных проектов, которые не осуществимы усилиями одного предприятия [4, с.331].

Реализация предложенных мероприятий будет содействовать положительному развитию взаимовыгодных связей между предприятиями, обеспечит трансформацию технологического уклада и рост предложения необходимых видов производства товаров, повысит их качество в условиях конкуренции, сформирует устойчивые взаимосвязи продвижения продукции промышленного предприятия. Переход к более высокой эффективности взаимодействия обеспечивается при условии достижения баланса интересов, полномочий и ответственности субъектов предприятия [3, с.72]. Отмечается, что предложенные рекомендации универсальны и применимы не только для рассматриваемого предприятия, но и для других традиционных представителей химической промышленности.

Таким образом, выход промышленного предприятия из кризиса рассматривается как комплекс согласованных действий руководителей и специалистов по осуществлению целесообразной трансформации технологического уклада.

\section{Благохарности}

Исследование выполнено при поддержке гранта Президента РФ по государственной поддержке ведущих научных школ РФ № НШ-2702.2020.6 «Концептуальные основы новой парадигмы экономического развития в эпоху технологической и социальной трансформации» 


\section{ЛИТЕРАТУРА}

1. Бондаев И.А., Морозова В.Д. Трансформация технологических укладов в процессе развития промышленности России // Экономика и предпринимательСтв0. 2017. № 12-3 (89). С. 144-148.

2. Воздействие пандемии COVID-19 на промышленность и экологию: [Электронный ресурс] // Режим доступа: www.ach.gov.ru (Дата 06ращения 07.08.2020)

3. Коркина Т.А., Лапаева 0.А. Организационно-экономический уклад: сущность, понятие и роль в развитии угледобывающего предприятия // Вестник Челябинского государственного университета. 2015. № 1 (356). С. 71-76.

4. Любицкая В.А. Трансформация внутрисистемного пространства промышленного предприятия в кризисных условиях // Вестник алтайской науки. 2015. № 3-4 (25-26). С. 330-334.

5. Орехова С.В., Романова 0.А. Трансформация бизнес-модели промышленного предприятия на разных стадиях жизненного цикла // Управленец. 2016. № 5 (63). C. 2-15.

6. Перепечаева Е.С., Симоненко Е.С. Оценка и управление конкурентоспособностью промышленного предприятия // Известия Юго-Западного государственного университета. 2012. № 5-2 (44). С. 298-306.

7. Производители спанбонда в России: [Электронный ресурс] // Режим доступа: www.o-zavodah.ru /(Дата обращения 07.08.2020)

\footnotetext{
(c) Андросова Ирина Владимировна (irinka-rusik@mail.ru), Положенцева Юлия Сергеевна (polojenceva84@mail.ru), Калимов Олег Владимирович (о_kalimov@mail.ru), Шевцов Алексей Николаевич (aleksey_shevtsov95@mail.ru). Журнал «Современная наука: актуальные проблемы теории и практики»
}

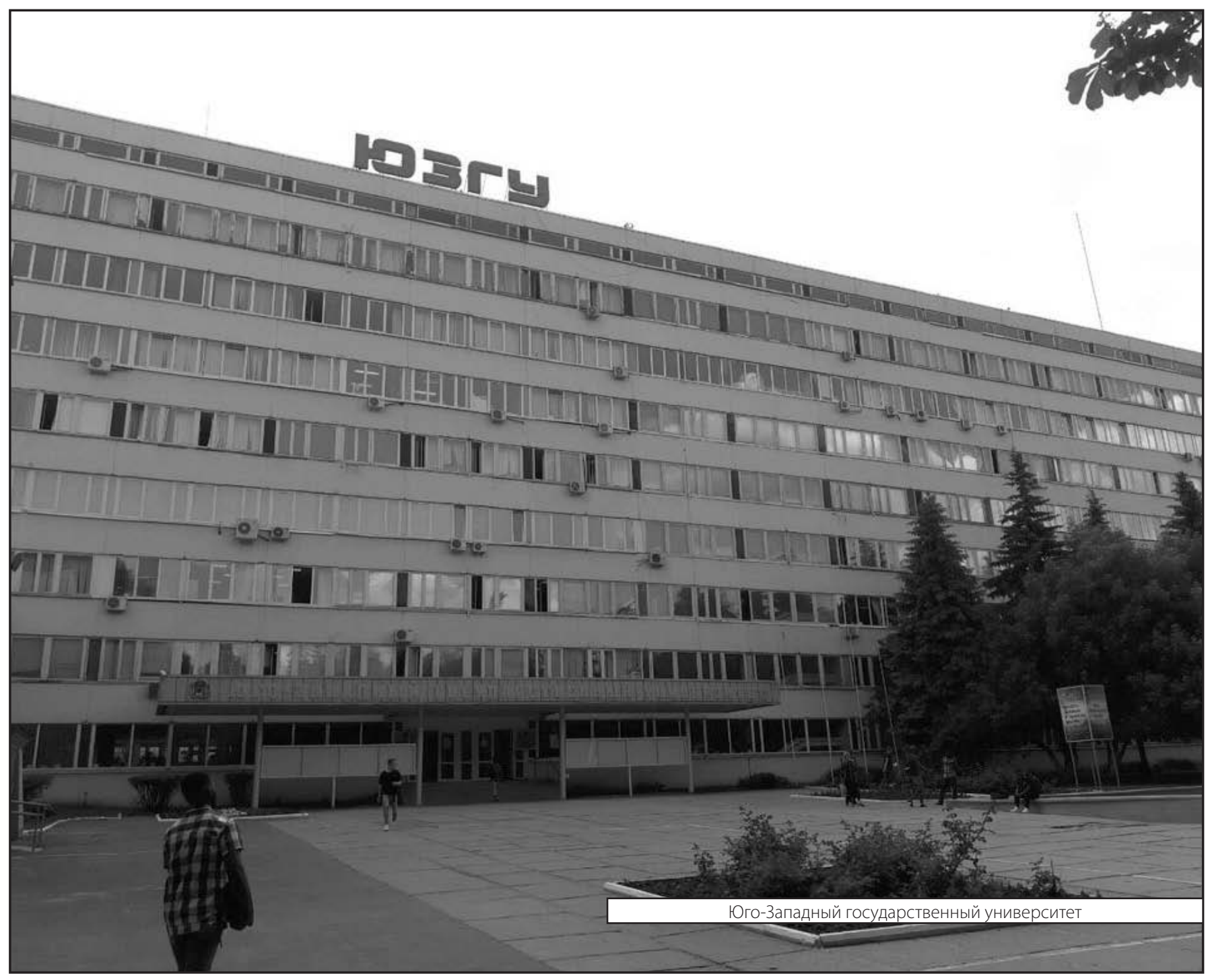

